\title{
Receptor Specific Clearance by the Reticuloendothelial System in Chronic Liver Diseases
}

\author{
DEMONSTRATION OF DEFECTIVE C3b-SPECIFIC \\ CLEARANCE IN PRIMARY BILIARY CIRRHOSIS
}

\author{
Charles J. Jaffe, John M. Vierling, E. Anthony Jones, Thomas J. Lawley, and \\ MICHAEL M. FraNK, The Laboratory of Clinical Investigation, National Institute \\ of Allergy and Infectious Diseases; the Section on Diseases of the Liver, Digestive \\ Diseases Branch, National Institute of Arthritis, Metabolism, and Digestive \\ Diseases; and the Dermatology Branch, National Cancer Institute; National \\ Institutes of Health, Bethesda, Maryland 20014
}

A B S T RACT An approach to the assessment of reticuloendothelial function that quantitates clearance specifically mediated by membrane receptors for $\mathrm{C} 3 \mathrm{~b}$ and immunoglobulin (Ig)G has been applied in man. Clearance of isologous erythrocytes coated with IgM or C3b or coated with IgG were examined in patients with primary biliary cirrhosis (PBC), chronic hepatitis, or alcoholic cirrhosis and normal control subjects and compared with the clearance of aggregated human serum albumin. Clearance of these three types of particles varied independently. None of the patients studied had a defect in the clearance of aggregated albumin. No patient with PBC (0:6) had delayed clearance of IgG-coated erythrocytes; one of six patients with chronic hepatitis had delayed clearance of these cells. Indeed, four of six with PBC had increased rates of IgG-mediated clearance. In contrast, six out of six patients with PBC had an unequivocal defect in clearance mediated by $\mathrm{C} 3 \mathrm{~b}$ receptors. The patients with PBC varied widely in terms of duration of symptoms, degree of cholestasis, and histologic stage of disease. No defect of C3b-mediated erythrocyte clearance was found in the patients with chronic hepatitis or alcoholic cirrhosis. Furthermore, a patient with severe cholestasis secondary to large duct biliary obstruction exhibited normal C3b-mediated clearance.

This study was presented, in part, at the 33rd Annual Meeting of the American Federation for Clinical Research in May 1976. Portions of this study have also appeared in abstract form in April 1976 (Clin. Res. 24: 330A.) and in April 1977 (Clin. Res. 25: 357A.).

Received for publication 23 January 1978 and in revised form 14 June 1978.
The defect in C3b-mediated clearance in PBC did not correlate with serum levels of individual complement components or inhibitors or with the presence of circulating immune complexes as measured by the $\mathrm{Clq}$ precipitation assay. Thus, measurements of receptor specific clearance, but not clearance of aggregated proteins, have revealed a highly specific defect in reticuloendothelial function in PBC.

\section{INTRODUCTION}

In vivo techniques for assessing reticuloendothelial $(\mathrm{RE})^{1}$ function traditionally measure the rate of clearance of immunologically inert substances from the circulation. In animal and human studies, colloidal gold, colloidal lipids, chromic phosphate and carbon, aggregated albumin, and polystyrene beads have all been used (1-3). The clearance of these particles has not been shown to depend on any immunologically specific process of recognition. RE clearance, as measured by these methods, has been either normal or increased in most of the clinical entities examined (1-4). Even in diseases in which clearance dysfunction has been postulated (for example, in illnesses characterized by the persistence of large amounts of circulating immune complexes), these methods have not revealed any major defect (5). Thus, in general, the clinical usefulness of this approach has been limited.

In the study of $\mathrm{RE}$ function in man reported here, we

\footnotetext{
${ }^{1}$ Abbreviations used in this paper: $\mathrm{CH}$, chronic hepatitis; $\mathrm{CH}_{50}$, total serum complement hemolytic activity; HBsAg, hepatitis B surface antigen, $\mathrm{PBC}$, primary biliary cirrhosis; $\mathrm{RE}$, reticuloendothelial.
} 
have applied techniques that measure the clearance of particles from the circulation by macrophage-receptor specific mechanisms. These new techniques have evolved from experiments that examined the factors regulating the clearance of antibody-coated cells in the autoimmune hemolytic anemias (6). The results of these experiments emphasized the role of specific membrane receptors for immunoglobulin and complement on fixed macrophages of the liver and spleen in the in vivo clearance of antibody-sensitized erythrocytes. The reagents developed in these studies can be used to assess in quantitative terms the ability of fixed splenic and hepatic macrophages to remove from the circulation particulate material with surface-bound antibody and complement.

In this study, patients with either primary biliary cirrhosis (PBC) or chronic hepatitis $(\mathrm{CH})$ were evaluated. Both of these chronic hepatocellular diseases are associated with defects of humoral and cellmediated immunity $(7-10)$. Three categories of control subjects were also studied: $(a)$ normal individuals, $(b)$ patients with chronic hepatocellular disease associated with alcoholism, and $(c)$ a patient with cholestasis not caused by PBC. The results demonstrate a striking immunospecific defect in the clearance of C3b-coated erythrocytes in patients with PBC.

\section{METHODS}

\section{Subjects}

Normal male and female volunteers between the ages of 18 and $25 \mathrm{yr}$ were hospitalized at the Clinical Center of the National Institutes of Health. All were in good health and had normal physical examinations and routine hematologic and serum biochemical test results.

Patients with PBC, chronic active hepatitis, alcoholic cirrhosis, and large duct biliary obstruction were hospitalized either at the Clinical Center or the Veterans Administration Hospital, Washington, D. C. The diagnosis of each patient was based on the presence of typical clinical, serum biochemical, serologic, hepatic histologic, and, where appropriate, cholangiographic findings. Relevant clinical and laboratory data are given in Table I. No patient showed evidence of hepatic decompensation at the time of these studies. Interpretations of liver biopsies and the determination of histologic stages of PBC were according to the criteria of Scheuer (12). All patients' sera were negative for hepatitis B surface antigen ( $\mathrm{HBsAg}$ ) by radioimmunoassay and were free of antibody to HBsAg and hepatitis B core antigen (13). None of the patients were on any drugs, which are known to have an effect on RE function or to alter hepatic histology (Table I).

\section{Antibodies}

Immunoglobulin (Ig)M isoagglutinins. Anti-A complementfixing IgM isoagglutinins were purified and characterized as. reported in detail elsewhere (14). Briefly, high-titer HBsAg negative antisera were obtained from individual donors through Ortho Diagnostics Inc., Raritan, N. J. High-titer IgM antibody, free of IgG contamination, was isolated with $5.4 \mathrm{M}$ ammonium sulfate precipitation followed by Sephadex G-200 (Pharmacia Fine Chemicals Inc., Piscataway, N. J.) column chromatography and sucrose density gradient ultracentrifugation. The resulting material had $2 \times 10^{11}$ biologically active isoagglutinin molecules per $\mathrm{ml}$ of the sucrose-veronalbuffered saline buffer, as assessed by the $\mathrm{Cl}$ fixation and transfer test (15). Antibody at a dilution of 1:15 in sterile saline was added to an equal volume of a suspension of erythrocytes at a concentration chosen to yield 40 IgM molecules per erythrocyte.

IgM cold agglutinins. The cold agglutinin used was isolated from the serum of a patient with idiopathic cold agglutinin syndrome. The procedures used in purification and characterization of the antibody have been previously described (16). The dilution of IgM cold agglutinin generated $150 \mathrm{Cl}$-fixing sites per erythrocyte. The erythrocytes were then incubated in autologous serum at $16^{\circ}$ and $37^{\circ} \mathrm{C}$ as described (16). Under these conditions, C3b-dependent erythrocyte clearance, comparable with that achieved with isoagglutinin, was obtained.

IgG anti-Rh antibody. High titer antisera, obtained from individual, HBsAg negative, Rho Gam donors, with $R h D$ specificity (Somerset Laboratories, Trenton, N. J.) was purified by sequential ammonium sulfate precipitation, Sephadex G-200 (Pharmacia Fine Chemicals Inc.) chromatography, and sucrose density gradient ultracentrifugation. The specificity of the antibody was determined by standard tests performed with panels of erythrocytes of known specificity. To ensure that the antibodies were monospecific for the Rh D antigen, adsorptions with erythrocytes bearing the Cde phenotype were performed when necessary. Erythrocytes were sensitized with anti-Rh $\mathrm{D}$ at a concentration chosen to yield about 2,500 molecules of IgG per erythrocyte.

All antibody solutions were sterilized by Millipore filtration (Millipore Corporation, Bedford, Mass.) and tested for pyrogen by rabbit fever and limulus assay before use.

Quantitation of the number of antibody molecules per erythrocyte. The $\mathrm{Cl}$ fixation and transfer test was used to quantitate the average number of complement-fixing IgM isoagglutinin molecules that were bound to each erythrocyte, as has been described elsewhere (15). The functional activity of the IgM cold agglutinin was determined by a modification of the $\mathrm{Cl}$ fixation and transfer method, which involved fixation at $16^{\circ} \mathrm{C}$ rather than $37^{\circ} \mathrm{C}$. The number of IgG anti-Rh antibody molecules bound per erythrocyte was determined by directly measuring the uptake of ${ }^{125}$ I-labeled (17) anti-Rh D antibody.

\section{Erythrocyte clearance studies}

Clearance of IgG anti-Rh D-coated autologous erythrocytes was used to test the functional integrity of the IgG Fc receptors on cells of the RE system, whereas clearance of IgM isoagglutinin or IgM cold agglutinin-sensitized autologous erythrocytes was used to assess the clearance mediated by $\mathrm{C} 3 \mathrm{~b}$ receptors $(6,14,16)$. The techniques involved in measuring the clearance of erythrocytes sensitized with IgM isoagglutinin (14) or IgM cold agglutinin (16) have been reported elsewhere.

Blood, obtained by venipuncture, was taken into acid citrate dextrose solution (U.S. Pharmacopeia formula A). With aseptic technique, erythrocytes were separated by sedimenting at $1,000 \mathrm{rpm}$ for $5 \mathrm{~min}$ at $4^{\circ} \mathrm{C}$ and then suspended in chilled saline at a concentration of $6.6 \times 10^{8} \mathrm{cells} / \mathrm{ml}$. The cell suspension was labeled with ${ }^{51} \mathrm{Cr}$ by incubating at $37^{\circ} \mathrm{C}$ for $30 \mathrm{~min}$ with 10 $\mu \mathrm{Ci}$ of sodium ${ }^{51} \mathrm{Cr}$ chromate (E. R. Squibb and Sons, Princeton, N. J.) per $\mathrm{ml}$ of cell suspension and washed four times in cold saline. An equal volume of a solution of antibody 
TABLE I

Patient Population Characteristics*

\begin{tabular}{|c|c|c|c|c|c|c|c|c|c|c|c|}
\hline \multirow{3}{*}{ Patient } & \multirow{3}{*}{ Age } & \multirow{3}{*}{ Sex } & \multirow{3}{*}{ Diagnosis } & \multicolumn{3}{|c|}{ Serum biochemical tests } & \multirow{2}{*}{\multicolumn{4}{|c|}{ Serological tests }} & \multirow{3}{*}{$\begin{array}{c}\text { Pertinent } \\
\text { medication }\end{array}$} \\
\hline & & & & Total & Alkaline & & & & & & \\
\hline & & & & & & SGPT & MA & SMA & Anti-HBs & Anti-HBc & \\
\hline & $y r$ & & & & & & & & & & \\
\hline A.C. & 53 & $\mathbf{F}$ & PBC, stage IV & 5.7 & 444 & 81 & + & + & _- & - & - \\
\hline P.M. & 49 & $\mathbf{F}$ & PBC, stage I-II & 0.5 & 220 & 152 & - & - & - & - & - \\
\hline J.T. & 55 & $\mathbf{F}$ & PBC, stage III & 5.4 & 400 & 85 & + & + & + & - & - \\
\hline E.K. & 39 & $\mathbf{F}$ & PBC, stage I & 0.8 & 590 & 270 & + & - & - & - & - \\
\hline S.S. & 45 & $\mathbf{F}$ & PBC, stage I-II & 0.4 & 177 & 82 & + & - & - & - & - \\
\hline W.W. & 38 & $\mathbf{F}$ & PBC, stage III & 1.1 & 192 & 101 & - & + & - & - & - \\
\hline J.W. & 45 & $\mathbf{F}$ & PBC, stage II & 2.3 & 390 & 138 & + & - & - & - & - \\
\hline E.S. & 51 & $\mathbf{M}$ & $\mathrm{CAH}$ & 1.0 & 230 & 290 & - & + & - & - & - \\
\hline J.M. & 20 & $\mathbf{F}$ & CAH, cirrhosis & 0.8 & 56 & 50 & - & + & - & - & $\begin{array}{l}\text { Prednisone, } \\
5 \text { mg by } \\
\text { mouth } \\
\text { every dav. }\end{array}$ \\
\hline P.A. & 21 & $\mathrm{~F}$ & $\mathrm{CAH}$, cirrhosis & 0.3 & 36 & 14 & - & - & - & - & $\begin{array}{l}\text { Prednisone, } \\
5 \mathrm{mg} \text { by } \\
\text { mouth } 4 \\
\text { times a day. }\end{array}$ \\
\hline G.B. & 55 & $\mathbf{M}$ & CAH & 0.8 & 41 & 142 & - & - & - & - & - \\
\hline L.S. & 27 & $\mathrm{~F}$ & CAH & 0.6 & 34 & 185 & - & + & + & + & - \\
\hline F.C. & 48 & $\mathbf{F}$ & $\mathrm{CAH}$ & 0.8 & 118 & 290 & - & - & - & - & - \\
\hline S.W. & 54 & $\mathrm{~F}$ & $\mathrm{CPH}$ & 0.3 & 60 & 58 & - & - & + & - & - \\
\hline M.B. & 55 & $\mathbf{M}$ & Alcoholic cirrhosis & 0.4 & 57 & 65 & ND & ND & ND & ND & - \\
\hline J.E. & 54 & $\mathbf{M}$ & Alcoholic cirrhosis & 2.3 & 136 & 35 & ND & ND & ND & ND & - \\
\hline B.W. & 46 & $\mathbf{M}$ & $\begin{array}{l}\text { Large duct biliary } \\
\text { obstruction: } \\
\text { chronic } \\
\text { pancreatitis }\end{array}$ & 5.1 & 1,515 & $\mathrm{ND}$ & ND & ND & ND & ND & - \\
\hline
\end{tabular}

* Abbreviations used in this table: SGPT, serum glutamic pyruvate transaminase; MA, mitochondrial antibody; SMA, smooth muscle antibody; anti-HBs, antibody against hepatitis B surface antigen; anti-HBc, antibody against hepatitis B core antigen; PBC, primary biliary cirrhosis; CAH, chronic active hepatitis as defined by Boyer (11); CPH, chronic persistent hepatitis as defined by Boyer (11); ND, not done.

† Milligrams per $100 \mathrm{ml}$ serum, normal range 0.1-1.2.

\$International Units per liter, normal range $10-78$.

"International Units per liter, normal range 2-45.

-, Negative.

at a fixed dilution was added drop-wise to a suspension of the radiochromated erythrocytes $\left(3.3 \times 10^{8}\right.$ cell $\left./ \mathrm{ml}\right)$ and incubated for $30 \mathrm{~min}$ at $37^{\circ} \mathrm{C}$. After incubation, the cells were washed twice in sterile, pyrogen-free saline.

With IgM cold agglutinin, antibody was first added to the radiochromium-labeled erythrocyte suspension $\left(3.3 \times 10^{8}\right.$ cells $/ \mathrm{ml}$ ) and incubated for $15 \mathrm{~min}$ at $16^{\circ} \mathrm{C}$. Without washing the cells, an equal volume of fresh autologous serum (as a source of complement) was added. This mixture was then incubated for $15 \mathrm{~min}$ at $16^{\circ} \mathrm{C}$ followed by $15 \mathrm{~min}$ at $37^{\circ} \mathrm{C}$ to allow the cold agglutinin to dissociate. With a positive immune adherence reaction (18) and direct agglutination with antibody to $\mathrm{C} 3 \mathrm{c}$, we have shown such cells to be coated with $\mathrm{C} 3 \mathrm{~b}$.

After washing, $1 \mathrm{ml}$ of a suspension of radiochromated, sensitized erythrocytes (that contain about $3.3 \times 10^{8}$ cells) was diluted 10-fold with cold saline and injected intravenously into an antecubital vein. 10 samples of venous blood were taken via a heparin lock during the ensuing $2 \mathrm{~h}$. The erythro- cyte survival was calculated from the radioactivity in blood samples as recommended by the International Committee for Standardization in Hematology (19). Those patients with blood group $\mathrm{O}$ were studied with cold agglutinin-sensitized cells; all others were studied with isoagglutinin-sensitized cells.

\section{Microaggregated albumin clearance studies}

The technique used for the measurement of the clearance of microaggregated human serum albumin was a modification of previously published methods (20). The microaggregated human albumin used was from one batch prepared by the Pharmaceutical Development Branch of the National Institutes of Health by a previously reported method (20) and was radiolabeled by E. R. Squibb and Sons. The material was prepared for parenteral use in humans by the Radiopharmaceutical Section of the Clinical Center. Assays for sterility, 
pyrogenicity, and specific activity were performed before administration. Just before a study each subject received 0.5 $\mathrm{cm}^{3}$ Lugol's solution diluted in orange juice to block uptake of free radioiodine by the thyroid gland. Two doses of albumin were employed: a trace dose of $0.025 \mathrm{mg} / \mathrm{kg}$ body weight, the rate of clearance of which reflects hepatic blood flow $(3,4,21)$, and a larger test dose of $5.0 \mathrm{mg} / \mathrm{kg}$, the rate of clearance of which has been used as a measure of RE phagocytic capacity $(3,4,21)$. After the intravenous administration of ${ }^{125}$ I-labeled microaggregated albumin, multiple samples of venous blood were drawn from a vein in the contralateral arm into heparinized syringes. The amount of radioactivity in trichloroacetic acid-precipitable plasma protein was plotted as a firstorder semilogarithmic function. The initial slope of this curve was taken as the measure of the rate of clearance of microaggregated albumin.

All clearance studies were approved by the clinical research and radiation safety committees of the National Institutes of Health and the Washington Veterans Administration Hospital and were conducted with the fully informed signed consent of each subject. In no case was any erythrocyte or albumin clearance study followed by any untoward reaction.

\section{Complement assays}

$\mathrm{C} 4$ and total serum complement hemolytic activity $\left(\mathrm{CH}_{50}\right)$ were assayed by hemolytic titration $(22,23)$. C3 was measured immunochemically with radial immunodiffusion plates and standards obtained from Behring Diagnostics, Inc., Somerville, N. J. The presence of antigenically detectable fragments of C3 in plasma was estimated by immunoelectrophoresis in $0.75 \%$ agarose, with rabbit antihuman C3 prepared in this laboratory, which was capable of recognizing both the C3c and the C3d determinants.

Levels of C3b inactivator were measured with a sensitive, newly developed radioimmunoassay which measures the release of radiolabeled $\mathrm{C} 3 \mathrm{c}$ from the cellular complement intermediate EAC43b (24). In brief, samples of the subject's plasma, diluted in EDTA buffer (23), were incubated for $1 \mathrm{~h}$ at $37^{\circ} \mathrm{C}$ with an equal volume of a suspension of the cellular complement intermediate EAC43b, which had been prepared from sheep erythrocytes, rabbit anti-Forssman IgM antibody, and purified human complement components including ${ }^{125} \mathrm{I}-\mathrm{C} 3$. After incubation, the extent of conversion of $\mathrm{C} 3 \mathrm{~b}$ to $\mathrm{C} 3 \mathrm{c}$ was determined. This is done by adding excess purified $\beta 1 \mathrm{H}$ protein and a proteolytic enzyme source (trypsin at $2.5 \mu \mathrm{g} / \mathrm{ml}$ ).

\section{Antigen-antibody complexes}

The presence of antigen-antibody complexes in serum was determined by the $\mathrm{Clq}$ precipitation test. $\mathrm{Clq}$ was purified from normal human serum as previously described (25) and labeled with ${ }^{125}$ I by a modification of the method of Bolton and Hunter (26). The precipitin procedure was performed as described by Zubler et al. (27).

All data were analyzed by previously reported methods (14).

\section{RESULTS}

Microaggregated albumin clearance. This is the standard technique used for study of RE function in man. The normal ranges (95\% confidence interval) for the initial half-life of the tracer and test doses of microaggregated albumin in plasma were $3.1-4.3 \mathrm{~min}$ and 19.7-31.0 $\mathrm{min}$, respectively. The values obtained in pa- tients with $\mathrm{PBC}$ and $\mathrm{CH}$ are depicted in Fig. 1. None of the values in any of the patients studied fell outside of the appropriate normal ranges. Hence, by this method, no clearance defect was demonstrable in either of the patient groups. The two patients with alcoholic cirrhosis (M. B. and J. E.) had tracer dose values of 3.5 and $3.7 \mathrm{~min}$ and test dose values of 22 and 27 min, respectively, also within the normal range. The plasma $t_{1 / 2}$ values for the tracer dose of albumin agree closely with other data in normal humans for the plasma half-life of substances that are completely cleared by the liver, such as small doses of indocyanine green $(21,28)$.

IgG-mediated clearance. At the level of sensitization chosen, IgG-sensitized radiochromated erythrocytes underwent a monoexponential decline in the circulation during the first $2 \mathrm{~h}$ after their intravenous administration (Fig. 2). The half-life of the labeled cells in normal volunteers was $42 \pm 9$ min (mean $\pm 95 \%$ confidence interval). The corresponding values obtained in two groups of patients are shown in Fig. 3. None of the patients studied with PBC demonstrated delayed clearance. Indeed, in four of six patients with this disease, the rate of clearance of IgG-sensitized erythrocytes was accelerated. IgG-mediated clearance was normal in three of six patients with $\mathrm{CH}$. One patient (G.B.), not shown in the figure, with $\mathrm{CH}$ and with significantly diminished serum levels of functional C4 activity and whole complement activity

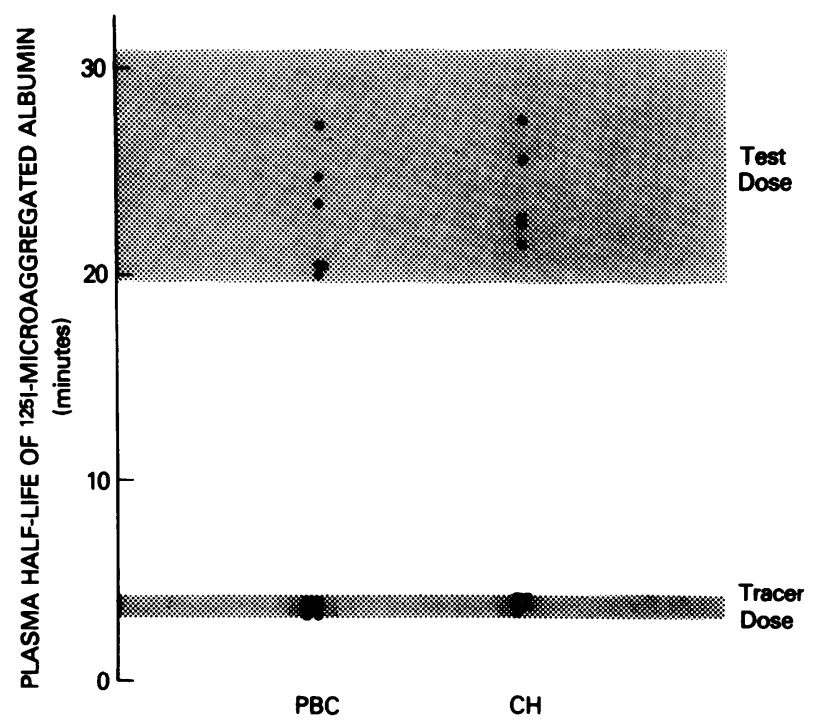

FIGURE 1 The half-lives of tracer and test doses of ${ }^{125}$ Ilabeled microaggregated albumin in plasma in six of the seven patients with PBC and five of the seven patients with $\mathrm{CH}$. The two shaded areas represent the respective ranges for these values in normal subjects. The half-life of the tracer dose $(0.025 \mathrm{mg} / \mathrm{kg})$ is an index of hepatic plasma flow, whereas the half-life of the test dose $(5.0 \mathrm{mg} / \mathrm{kg})$ is an index of nonspecific reticuloendothelial phagocytic function. 


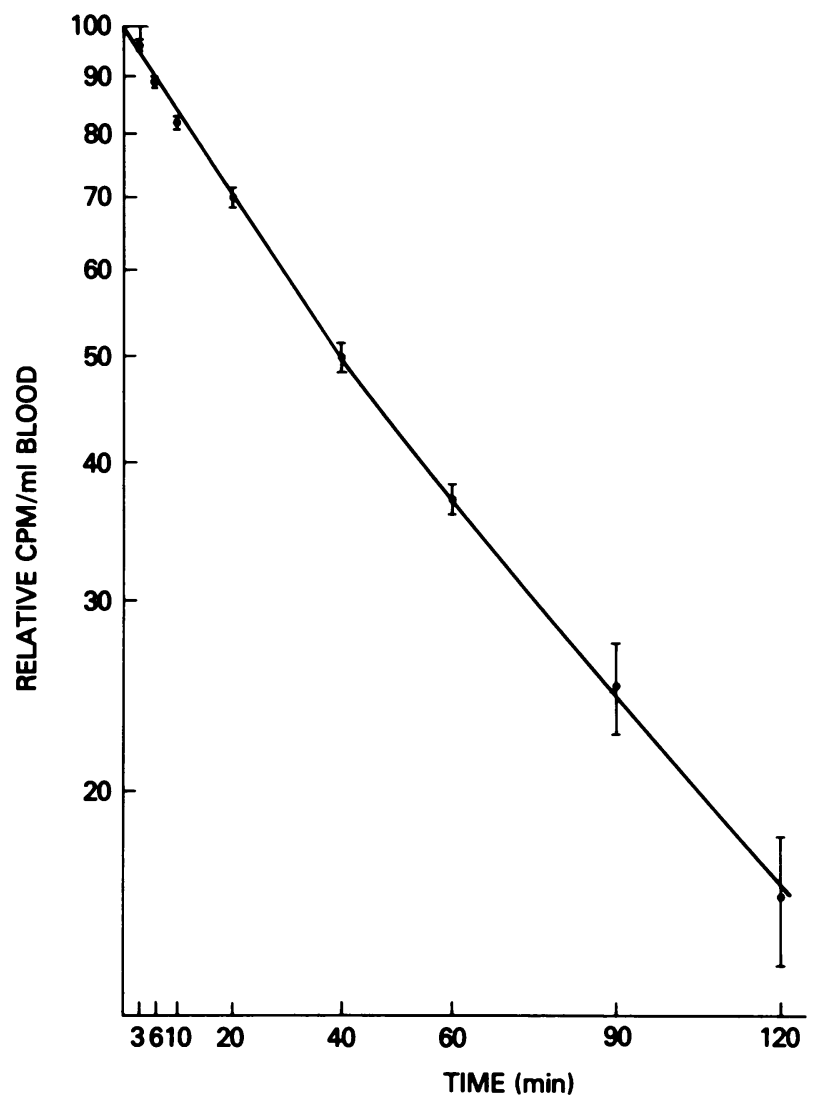

FIgure 2 The decline of radioactivity in the blood of a group of 10 normal subjects during the first $2 \mathrm{~h}$ after the intravenous administration of IgG-sensitized radiochromated autologous erythrocytes. Values for radioactivity per unit volume of blood are expressed as a percentage of the corresponding hypothetical value at zero time. Vertical bars represent the standard errors of means. Blood radioactivity undergoes a monoexponential decline.

$(<0.1 \%$ of normal) had a marked reduction in the rate of IgG-mediated clearance. Two patients with $\mathrm{CH}$ had accelerated clearance. The two patients with alcoholic cirrhosis (M.B. and J.E.) had normal clearance of IgG coated erythrocytes with $t_{1 / 2}$ values of 42 and 46 min, respectively.

$C 3 b$-mediated clearance. IgM-sensitized radiochromated erythrocytes rapidly become coated with $\mathrm{C} 3 \mathrm{~b}$ in vivo $(6,14,16)$. Measurement of whole blood radioactivity after the intravenous administration of these cells typically yields a biphasic curve, which is attributable to a rapid, initial disappearance of C3bcoated cells from the circulation followed by a gradual release of a proportion of the labeled cells back into the circulation. The released cells have a near normal survival in the circulation $(6,14,16)$. At the degree of antibody sensitization chosen, in normal subjects a large proportion of the sensitized erythrocytes were rapidly cleared during the first $10 \mathrm{~min}$ and the

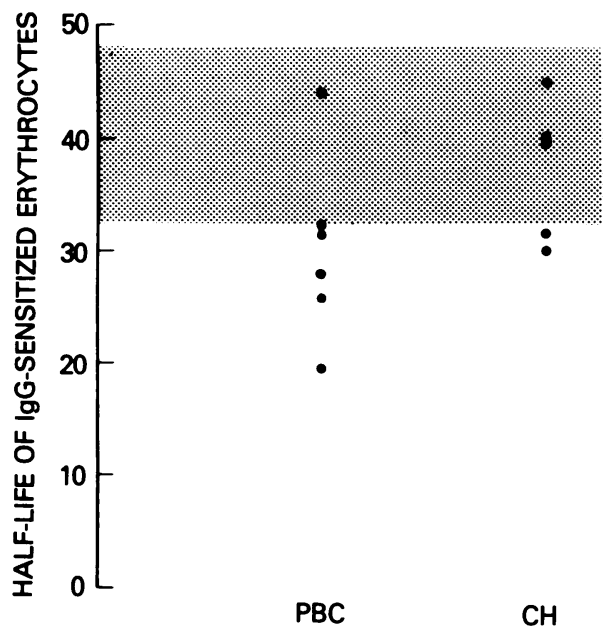

FIGURE 3 Clearance of IgG-sensitized radiochromated autologous erythrocytes from the circulation in six of the seven patients with PBC and five of the seven patients with $\mathrm{CH}$. Clearance values are expressed as the half-life of the labeled cells in the circulation. Not shown in this figure is the clearance in G.B., a patient with chronic active hepatitis who had a C4 titer of $1,000 \mathrm{U}$. This clearance curve was not monoexponential. No clearance was observed at $1 \mathrm{~h}$ and $15 \%$ of the cells were cleared at $2 \mathrm{~h}$. The shaded area represents the range for these values for a group of normal subjects.

number in the circulation reached a nadir between 10 and $20 \mathrm{~min}$ (Fig. 4). The nadir reflects the total proportion of cells sequestered and was taken as an index of clearance. The percentage of cells remaining in the

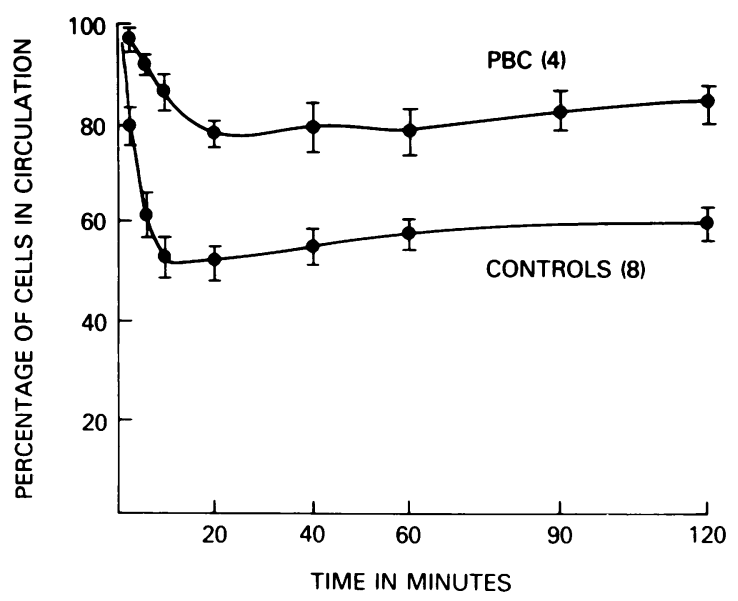

FIGURE 4 Clearance of IgM-sensitized radiochromated autologous erythrocytes from the circulation. Radioactivity per unit volume of blood is expressed as a percentage of the hypothetical value at zero time. Shown is the mean $\pm 1 \mathrm{SE}$ for eight normal control subjects whose erythrocytes were sensitized with IgM anti-A isoagglutinin. Also shown is the mean $\pm 1 \mathrm{SE}$ for four patients with $\mathrm{PBC}$ whose cells were sensitized with anti-A isoagglutinin. The initial disappearance rate of radioactivity is much slower and the nadir of blood radioactivity appreciably higher $(P<0.001)$ in the patients with $\mathrm{PBC}$ than in the normal subjects. 
circulation at the nadir in normal subjects ranged from 36 to $64 \%$ with isoagglutinin and from 25 to $59 \%$ with the cold agglutinin. The mean $\pm 1 \mathrm{SE}$ for four patients with PBC are shown in Fig. 4. The results for individual patients with $\mathrm{CH}$ and $\mathrm{PBC}$ are shown in Fig. 5. Not shown in the figure are the results for two patients with alcoholic cirrhosis who had values of 49 and $51 \%$. Values for each of the four patients studied with $\mathrm{CH}$ and the two patients with alcoholic cirrhosis were less than $65 \%$. In contrast, corresponding values in each of the six patients with $\mathrm{PBC}$ who were studied were greater than $70 \%$, which indicates a defect in complement-dependent clearance. It was possible to study one patient with severe cholestasis of 6-wk duration because of chronic large duct biliary obstruction secondary to chronic pancreatitis. Only $31 \%$ of the cells injected into this patient remained in the circulation at the nadir, which demonstrates that the clearance defect in PBC was not caused by cholestasis, per se.

Complement studies. Normal ranges were obtained by studying normal, healthy blood bank donors. Levels of complement in plasma samples obtained at the time of the clearance studies are summarized in Fig. 6. In patients with $\mathrm{PBC}$ there was no depression in serum complement. Indeed, in several patients C3 levels in serum were increased, an observation in agreement with other data (29). Except for one patient with $\mathrm{CH}$, not shown in the figure, in whom the total hemolytic complement was $0 \mathrm{CH}_{50} \mathrm{U}$ and hemolytically active $\mathrm{C} 4$ was less than 1,000 hemolytic $\mathrm{U}$, levels of complement were not decreased in any patient group. In addition, four of the seven patients with

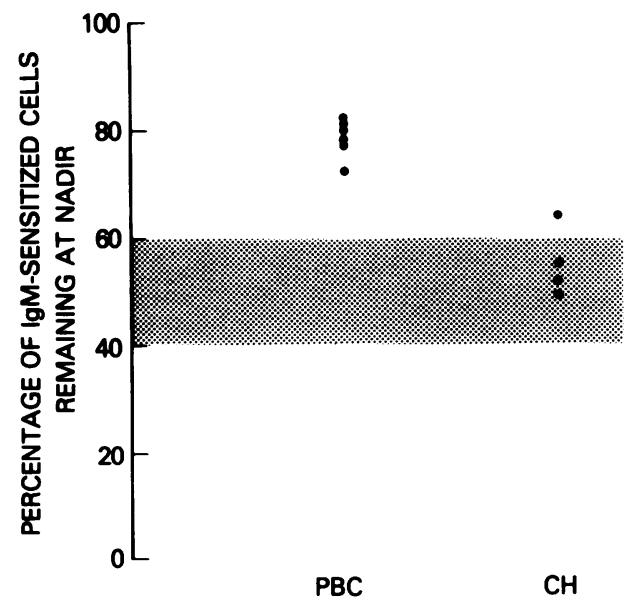

FIGURE 5 Clearance of IgM-sensitized radiochromated autologous erythrocytes from the circulation in six of the seven patients with PBC and four of the seven patients with $\mathrm{CH}$. Clearance is expressed as radioactivity per unit volume of blood at the nadir of the clearance curve expressed as a percentage of the corresponding hypothetical value for blood radioactivity at zero time. The shaded area represents the range for these values in a group of normal subjects.
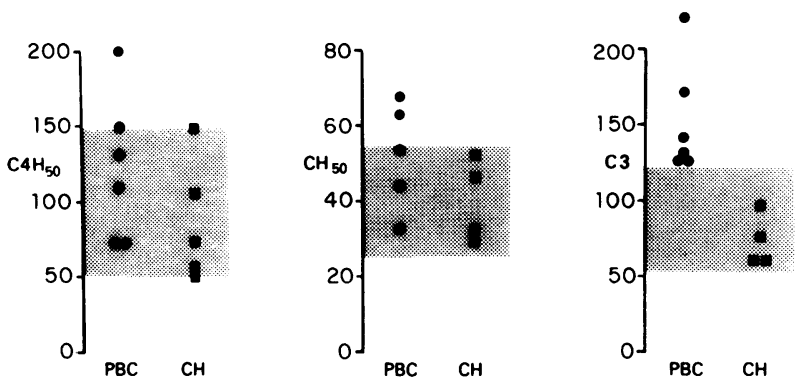

Figure 6 Serum $\mathrm{C} 4$ hemolytic activity $\left(\mathrm{C}_{4} \mathrm{H}_{50}\right), \mathrm{CH}_{50}$, and serum $\mathrm{C} 3$ concentration (milligrams $/ 100 \mathrm{ml}$ ) in the patients with $\mathrm{PBC}$ and $\mathrm{CH}$. The shaded areas represent the ranges of values in groups of normal subjects.

PBC were found to have demonstrable plasma levels of the cleavage product of C3, C3c. Similar findings were not observed in the plasma of patients studied with the other diseases, nor in the plasma of normal blood donors.

Five of seven patients with PBC and four of six patients with chronic active hepatitis, had evidence of increased ${ }^{125} \mathrm{I}-\mathrm{Clq}$ binding (Fig. 7). There was no

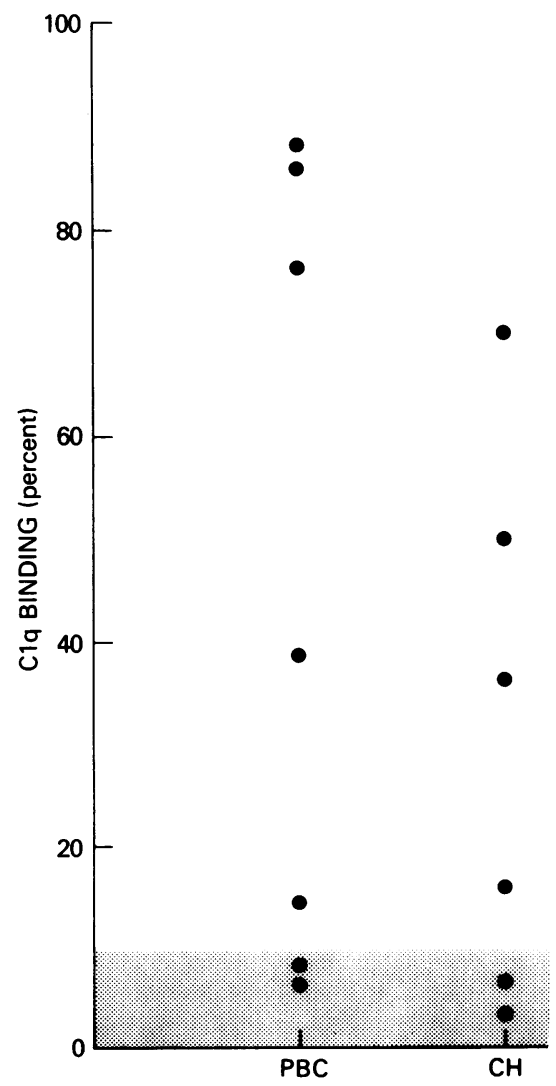

FIGURE 7 Binding of Clq by the sera of the patients with $\mathrm{PBC}$ and $\mathrm{CH}$. The shaded area represents the corresponding range for $\mathrm{Clq}$ binding given by sera from a group of normal subjects. 
correlation between the levels of immune complexes and clearance rates. Also there was no correlation between $\mathrm{C} 3 \mathrm{~b}$ inactivator titers and clearance rates. Titers ranged from 955 to $1,130 \mathrm{U} / \mathrm{ml}$ in patients with $\mathrm{PBC}$ and from 800 to $1,070 \mathrm{U} / \mathrm{ml}$ in patients with $\mathrm{CH}$. In neither of these groups do the values differ from normal.

\section{DISCUSSION}

The present study reports quantitative data on reticuloendothelial clearance capacity in chronic liver diseases obtained by techniques that are dependent upon specific $\mathrm{RE}$ cell surface receptors and which permit specific functions mediated by hepatic and splenic RE cells to be measured independently. Previous studies had indicated that the clearance from the circulation of erythrocytes coated with antibody and (or) complement was not dependent upon intravascular hemolysis, but rather on their specific binding to $\mathrm{RE}$ cell receptors for the Fc portion of IgG or C3b bound to the erythrocyte surface. Clearance of IgM isoagglutinin and IgM cold agglutinin sensitized erythrocytes required complement activation. The complement coated erythrocytes adhered to Kupffer cell membranes during their passage through the liver. A portion of the Kupffer cell-adherent erythrocytes were phagocytosed and the remainder were released into the circulation as a consequence of the cleavage of $C 3 b$ by the $\mathrm{C} 3 \mathrm{~b}$ inactivator in the circulation $(6,14,16)$. In contrast, $\mathbf{F c}$-specific clearance of IgG-coated erythrocytes was mediated predominantly by splenic RE cells. Sequestered IgG-coated erythrocytes underwent phagocytosis without being released back into the circulation (6). We believe that the C3 fragment, C3d, may contribute to the splenic clearance, although this point remains controversial.

The application of these techniques to patients with chronic liver disease demonstrated a striking defect in the C3b-specific clearance function of Kupffer cells in $\mathrm{PBC}$, whereas this function was normal in patients with $\mathrm{CH}$ and control subjects with compensated alcoholic cirrhosis or cholestasis caused by large duct biliary obstruction. Furthermore, this defect was selective because $\mathrm{Fc}$-receptor-mediated clearance as well as the clearance of aggregated albumin was normal or increased in the patients with the C3b-specific defect.

Determination of the plasma disappearance rate of microaggregated albumin is the standard procedure used to assess RE function in man. A tracer dose of microaggregated albumin does not present an appreciable phagocytic load to the RE system and its rate of clearance serves as an index of hepatic blood flow (1-4, 21 ). The fact that clearance of the tracer dose was normal in the patients studied is consistent with other clinical and laboratory data which indicated that they were not in a state of hepatic decompensation. The test dose of microaggregated albumin is used to assess nonspecific phagocytic function. Its clearance would be expected to be abnormal if the general phagocytic function of the RE system were impaired. The normal values for the clearance of the test dose indicate the presence of intact mechanisms for the phagocytosis of colloids in the circulation in all of the subjects studied. Thus, studies with receptor-specific clearance techniques have detected defects of RE function which could not be identified by conventional assessment of the phagocytosis of microaggregates alone.

The patients with PBC included individuals with early, asymptomatic, precirrhotic disease as well as late, symptomatic disease which had progressed to established cirrhosis. The clearance defect did not correlate with the duration of symptoms attributable to the disease, with serum biochemical indices of cholestasis, or with the histologic stage of the disease. The presence of cholestasis is not an adequate explanation for the defect because C3b-specific clearance was entirely normal in a patient with marked cholestasis caused by large duct biliary obstruction. Furthermore, the defect was not associated with either low serum levels of complement components or increased activity of $\mathrm{C} 3 \mathrm{~b}$ inactivator in serum.

There are several possible mechanisms which might explain the defect in C3b-specific clearance in PBC. The data are entirely consistent with reduced number, affinity, or availability of $\mathrm{C} 3 \mathrm{~b}$ receptors. It appears that in patients with PBC the number of Kupffer cells is not decreased (30). Our own albumin clearance data would suggest that this is the case. A second possibility is suggested by the observation that cleavage products of $\mathrm{C} 3$, which may include $\mathrm{C} 3 \mathrm{~b}$ or $\mathrm{C} 3 \mathrm{c}$, are detectable in the serum of patients with PBC and in some patients with $\mathrm{CH}$ (31). The presence of increased quantities of circulating C3 fragments suggests that competitive inhibition of $\mathrm{C} 3 \mathrm{~b}$ receptors by C3 fragments may explain the C3b-specific defect observed here. In support of this concept, Potter et al. (32) have observed increased fractional and absolute catabolic rates of $\mathrm{C} 3$ in a group of patients with $\mathrm{PBC}$ but not in HBsAg negative CH (33) as well as increases in the extravascular to intravascular pool ratios of $\mathrm{C} 3$ in a proportion of the patients with PBC (32). These findings are consistent with increased production of $\mathrm{C} 3$ fragments and with increased binding of C3 or its cleavage products to tissue $\mathrm{C} 3$ receptors in this disease. An alternative mechanism would be that circulating immune complexes that bear $\mathrm{C} 3 \mathrm{~b}$ may act as competitive inhibitors of C3b-receptors. However, we have found no relationship between C3bspecific clearance and the presence of circulating immune complexes as assessed by elevated serum $\mathrm{Clq}$ binding activity. 
In contrast to the marked defect seen for $\mathrm{C} 3 \mathrm{~b}$-specific clearance in $\mathrm{PBC}$ compared to $\mathrm{CH}$, the clearance of IgG-coated erythrocytes was not diminished in either of these diseases. In fact, several of the patients with PBC had augmented clearance of IgG-coated erythrocytes. The clearance rates of IgG-coated cells did not correlate with assessments of splenic size by either palpation or scintiphotography, although several patients in the PBC group did have appreciable splenomegaly. Because splenic enlargement in PBC may precede the onset of portal venous hypertension, it may be that activation of macrophages within the spleen contributes to splenomegaly. In animals whose macrophages have been activated by specific immunization, an increased clearance of IgG-sensitized cells has been reported (34).

None of the patients with PBC who had elevated Clq binding activity had decreased clearance of IgGcoated erythrocytes. These data are in marked contrast to recent observations in patients with systemic lupus erythematosis in whom the presence of elevated Clq binding activity was associated with the decreased clearance of IgG-coated erythrocytes (35). Further characterization of the composition of circulating immune complexes which are detectable in the various patient groups studied $(36,37)$ may provide new insights into pathogenetic mechanisms in these diseases.

\section{REFERENCES}

1. Biozzi, G., and C. Stiffel. 1965. The physiopathology of the reticuloendothelial cells of the liver and spleen. Prog. Liver. Dis. 2: 166-191.

2. Biozzi, G., B. Benacerraf, B. N. Halpern, C. Stiffel, and B. Hillemand. 1958. Exploration of the phagocytic function of the reticuloendothelial system with heat denatured human serum albumin labeled with $I^{131}$ and application to the measurement of liver blood flow, in normal man and in some pathological conditions. J. Lab. Clin. Med. 51: 230-239.

3. Sheagren, J. N., J. B. Block, and S. M. Wolff, 1967. Reticuloendothelial system phagocytic function in patients with Hodgkin's disease. J. Clin. Invest. 46: 855-862.

4. Wagner, H. N., Jr., M. Iio, and R. B. Hornick. 1963. Studies of the reticuloendothelial system (RES). II. Changes in the phagocytic capacity of the RES in patients with certain infections. J. Clin. Invest. 42: 427-434.

5. Salky, N. K., D. Mills, N. R. Di Luzio, and M. S. Oppenheim. 1965. Activity of the reticuloendothelial system in diseases of altered immunity. J. Lab. Clin. Med. 66: $952-960$.

6. Frank, M. M., A. D. Schreiber, J. P. Atkinson, and C. J. Jaffe. 1977. Pathophysiology of immune hemolytic anemia. Ann. Intern. Med. 87: 210-222.

7. Schaffner, F. 1975. Primary biliary cirrhosis. Clinics in Gastroenterology. 4: 351-366.

8. Plotz, P. H. 1975. Autoimmunity in hepatitis. Med. Clin. N. Am. 59: 869-876.

9. Smith, M. G. M., A. L. W. F. Eddleston, and R. Williams. 1975. Immunologic factors in the evolution of active chronic hepatitis and other autoimmune liver diseases. Clinics in Gastroenterology. 4: 297-313.

10. Reed, W. D., A. L. W. F. Eddleston, and R. Williams.
1974. Immunopathology of viral hepatitis in man. Prog. Med. Virol. 17: 38-76.

11. Boyer, J. L. 1976. Chronic hepatitis-a perspective on classification and determinants of prognosis. Gastroenterology. 70: 1161-1171.

12. Scheuer, P. J. 1973. Liver Biopsy Interpretation. The Williams and Wilkins Company, Baltimore. 33-38 and 66-73.

13. Hoofnagle, J. H., R. J. Gerety, and L. F. Barker. 1973. Antibody to hepatitis B virus core in man. Lancet. II: 869-873.

14. Atkinson, J. P., and M. M. Frank. 1974. Studies on the in vivo effects of antibody. Interaction of IgM antibody and complement in the immune clearance and destruction of erythrocytes in man. J. Clin. Invest. 54: 339-348.

15. Borsos, T., H. R. Colten, J. S. Spalter, N. Rogentine, and H. J. Rapp. 1968. The C'la fixation and transfer test: examples of its applicability to the detection and enumeration of antigens and antibodies at cell surfaces. J. Immunol. 101: 392-398.

16. Jaffe, C. J., J. P. Atkinson, and M. M. Frank. 1976. The role of complement in the clearance of cold agglutinin-sensitized erythrocytes in man. J. Clin. Invest. 58: $942-949$.

17. McFarlane, A. S. 1958. Efficient trace-labelling of proteins with iodine. Nature (Lond.). 182: 53.

18. Reynolds, H. Y., J. P. Atkinson, H. H. Newball, and M. M. Frank. 1975. Receptors for immunologlobulin and complement on human alveolar macrophages. J. Immunol. 114: 1813-1819.

19. Report by the International Committee for Standardization in Hematology Panel. 1971. Recommended methods for radioisotope red cell survival studies. Br. J. Haematol. 21: 241-250.

20. Briner, W. H. 1968. Preparation of ${ }^{125}{ }^{2}$-labeled microaggregated human serum albumin for use in studies of reticuloendothelial function in man. J. Nucl. Med. 9: 482-485.

21. Dobson, E. L., G. F. Warner, C. R. Finney, and M. E. Johnston. 1953. The measurement of liver circulation by means of the colloid disappearance rate. I. Liver blood flow in normal young men. Circulation. 7: 690-695.

22. Gaither, T. A., D. W. Alling, and M. M. Frank. 1974. A new one-step method for the functional assay of the fourth component (C4) of human and guinea pig complement. J. Immunol. 113: 574-583.

23. Mayer, M. M. 1964. Experimental Immunochemistry. E. A. Kabat and M. M. Mayer, editors. Charles C. Thomas Publisher, Springfield, Ill.

24. Gaither, T. A., J. Gadek, and M. M. Frank. 1978. C3b inactivator: The effect on cell bound $\mathrm{C} 3 \mathrm{~b}$ and a simplified functional assay. Abstracts of the 7th International Complement Workshop. J. Immunol. 120: 1774.

25. Yonemasu, K., and R. M. Stroud. 1971. Clq: rapid purification method for preparation of monospecific antisera and for biochemical studies. J. Immunol. 106: 304-313.

26. Bolton, A. E., and W. M. Hunter. 1973. The labelling of proteins to high specific radioactivities by conjugation to a ${ }^{125}$ I-containing acylating agent. Application to the radioimmunoassay. Biochem. J. 133: 529-538.

27. Zubler, R. H., and P. H. Lambert. 1976. The ${ }^{125 I-C l q}$ binding test for the detection of soluble immune complexes. In In Vitro Methods in Cell-Mediated and Tumor Immunity. B. R. Bloom and J. R. David, editors. Academic Press, Inc., New York. 565-572.

28. Martin, J. F., M. Mikulecky, T. F. Blaschke, J. G. Waggoner, J. Vergalla, and P. D. Berk. 1975. Differences between the plasma indocyanine green disappearance rates 
of normal men and women. Proc. Soc. Exp. Biol. Med. 150: 612-617.

29. Potter, B. J., A. M. Trueman, and E. A. Jones. 1973. Serum complement in chronic liver disease. Gut. 14: 451-456.

30. Foulk, W. T., and W. M. Baggenstoss. 1975. Biliary cirrhosis. In Diseases of the Liver. L. Schiff, editor. J. B. Lippincott Co., Philadelphia. 4th edition. 940-970.

31. Teisberg, P., and E. Gjone. 1973. Circulating conversion products of $\mathrm{C} 3$ in liver disease. Evidence for in vivo activation of the complement system. Clin. Exp. Immunol. 14: 509-514.

32. Potter, B. J., E. Elias, and E. A. Jones. 1976. Hypercatabolism of the third component of complement in patients with primary biliary cirrhosis. J. Lab. Clin. Med. 88: 427-439.

33. Elias, E., B. J. Potter, H. C. Thomas, and S. Sherlock. 1976. C3 metabolism in $\mathrm{HBsAg}$ positive and negative chronic active liver disease (CALD). Gut. 17: 389. (Abstr.)
34. Atkinson, J. P., and M. M. Frank. 1974. The effect of bacillus-Calmette-Guerin-induced macrophage activation on the in vivo clearance of sensitized erythrocytes. J. Clin. Invest. 53: 1742-1749.

35. Frank, M. M., C. J. Jaffe, R. P. Kimberly, T. J. Lawley, and P. H. Plotz. 1977. An immunospecific clearance defect in patients with systemic lupus erythematosus (SLE) related to the levels of circulating immune complexes (IC). Clin. Res. 25: 357A. (Abstr.)

36. Wands, J. R., J. L. Dienstag, A. K. Bhan, E. R. Feller, and K. J. Isselbacher. 1978. Circulating immune complexes and complement activation in primary biliary cirrhosis. N. Engl. J. Med. 298: 233-237.

37. Thomas, H. C., D. De Villiers, B. J. Potter, H. Hodgson, S. Jain, D. P. Jewell, and S. Sherlock. 1978. Immune complexes in acute and chronic liver disease. Clin. Exp. Immunol. 31: 150-157. 